\title{
Bitki Artıklarının Buğdayda Bipolaris sorokiniana, Fusarium culmorum ve Fusarium graminearum'un Neden Olduğu Kök Çürüklügüne Etkileri
}

\author{
Fikret DEMIRCl ${ }^{1}$ \\ F. Sara DOLAR ${ }^{1}$
}

Geliş Tarihi : 11.01.2002

\begin{abstract}
Özet: Farklı bitki artıkları (buğday, mercimek, nohut, arpa, fiğ, kolza ve yulaf) ile muamele edilen toprak ekstraktlarının laboratuvar koșullarında Bipolaris sorokiniana, Fusarium culmonum ve Fusarium graminearum' un misel gelișimlerine etkileri belírlenmiş̧tir. Bitki artıklarının tümú $F$, culmonum' un misel geliş̧imini teşvik etmiş̧tir. Ancak, yulaf, mercimek, arpa, kolza ve fiğ artıkları B. sorokiniana ve $F$, graminearum' un her ikisininde misel gelişimini değișik oranlarda engellemiștir. Saksılarda yärütolen denemelerde, bitki artıklarınin tümu, Uç hastalık etmeninin enfeksiyon oranlarının \% 8.92 ile \% 71.98 arasinda azalmasına neden olmuștur. Arpa, yulaf ve kolza artıkları bu üç patojenin neden olduğu kök çürükıăgu enfeksiyonlarını \% 41.49 ila 71.98 oranlarında engelleyerek en yöksek etkiye sahip olmuşlardır.
\end{abstract}

Anahtar Kelimeler: Bipolaris sorokiniana, Fusarium culmorum, Fusarium graminearum, bitki artıkları, buğday, kök çăräkläğo

\section{Effects of Plant Residues on Root Rot in Wheat Caused by Bipolaris sorokiniana, Fusarium culmorum and Fusarium graminearum}

\begin{abstract}
The effects of extracts of soil amended with different plant (wheat, lentil, chickpea, barley, rape, common vetch and oat) residues to mycelial growth of Bipolanis sorokiniana, Fusarium culmorum, Fusanium graminearum were determined in laboratory experiment. All the crop residues stimulated the mycelial growth of $F$. culmorum. However, oat, lentil, barley, common vetch and rape residues inhibited mycelial growth of $B$. sorokiniana and $F$. graminearum. In pot experiment, the disease incidence of the three root rot pathogens of wheat was reduced between 8.92 and $71.98 \%$ by all of the plant residues. Barley, oat and rape residues were found the most effective on $B$. sorokiniana, $F$. culmorum and $F$. graminearum. They reduced disease incidence of three pathogens up to 41.49 to $71.98 \%$.
\end{abstract}

Key Words: Bipolaris sorokiniana, Fusarium culmorum, Fusarium gramineanum, crop residue, wheat, root rot

\section{Giris}

Buğday (Triticum aestivum L.) danyada ve alkemizde en çok aretim alanı olan, en çok üretilen ónemli bir besin kaynağıdır. Ülkemizde toplam tarım alanının \%66.84'ü buğday ekiliş alanlarıdir (Anonim 1998). Buğday Üretiminin istenilen duzeye ulaşamamasının çeşitli nedenleri olmakla beraber Fusarium spp., Rhizoctonia spp., Pythium spp., Gaeumannomyces graminis var. tritici, Pseudocercosporella herpotrichoides, Bipolaris sorokiniana ve Alternaria spp.' nin neden olduğu kök ve kök boğazı hastalıkları bütun dünyada buğday üretimini sınırlayan ónemli faktörlerdendir. (Wiese 1987, Windels ve Holen 1989, Rush ve Mathieson 1990, Mamluk ve ark. 1997). Bu hastalıklarla mücadelede tohum ilaçlaması ve dayanıklı çeșit kullanımı önerilmekle beraber bu yöntemlerle toprak patojenlerinin etkin bir şekilde kontrolünön sağlanması oldukça güçtür (Wiese 1987. Rush ve Mathieson 1990, Weege ve ark 1991, Mauler-Machnik ve Zahn 1994). Sistemik fungisitler ile yapılacak tohum ilaçlaması tohumun ekilmesinden sonra ancak belirli bir muddet enfeksiyonlara karși bitkiyi korumaktadır.
Dayanıkhı çeșitlerin yetiştirilmesinde de bir takım sorunlarla karşılaşılmaktadır. Bunlardan en önemlisi patojenlerin yeni irklarının ortaya çıkması nedeniyle dayanıklı çeşitlerin bir süre sonra hassas reaksiyon göstermeleridir. Ayrıca çok sayıdaki toprak patojenlerinin tủmüne dayanıklı çeşitlerin üretilmesi oldukça güçtûr. Biyolojik mücadelenin diğer mucadele yöntemlerine alternatif teşkil edebileceği dūşünülmektedir. Toprak patojenlerinin biyolojik mücadelesinde etkili olan mikrobial akti-viteyi teşvik etmek amacıyla toprağa farkı organik mater-yallerin ilave edilmesi önerilmektedir (Huber ve Watson 1970, Linderman 1989). Toprağa ilave edilen organik materyallerin toprak kơkenli bitki patojenlerine karşı bazen artırıcı (Huber ve Anderson 1976, Linderman 1989, Singh ve ark. 1989), fakat çoğunlukla azaltıcı (Synder 1959, Davey ve Papavizas 1960, Gilpatrick 1969, Jarvis ve Thorpe 1981, Sun ve Huang 1985, Singh ve Nema 1987, Ramirez ve Villapudua Munnecke 1988, Linderman 1989, Singh ve ark. 1989, Dolar ve Demirci 1996, Williams-Woodward ve ark. 1997) etkiler gösterdiği bildirilmektedir.

\footnotetext{
${ }^{1}$ Ankara Óniv. Ziraat Fak, Bitki Koruma BölümU-Ankara
} 
Bu çalıșmada laboratuvar ve sera koşullarinda toprağa bitkisel artık uygulamalarının Fusarium culmorum, F. graminearum ve Bipolanis sorakiniena azerine etkilerinin belirlenmesi hedef alınmıștır.

\section{Materyal ve Yöntem}

Bltki artıklarının Bipolaris sorokiniana, Fusarium
culmorum, Fusarium graminearum'un kütü gelișimine etkllerinin belirlenmesi: Hasat sonrası Oretici tarlalarından toplanan nohut, mercimek, kolza, fig. buğday, arpa ve yulaf bitki artiklari $60^{\circ} \mathrm{C}$ ' de tamamen kurutulmuş ve değirmende ogătalmüștar. Herbir bitki artığı, toprak saksılarda bulunan steril olmayan tarla topră̌ının yüzeyinin $2,5 \mathrm{~cm}$ alt kısmına \% 1 (ağırlık/ağırlik) oraninda yayilmiştır. Saksilarda nem seviyesi \% 5 olacak şekilde destile su llaye edilmiştít. Saksılarda nem kaybıni engellemek amaeıyla ustleri şeffaf polietilen torbalarla kapatıldiktan sonra bitki artıklarının dekompoze olmaları için 5 hafta oda sicaklığında tutuimuşlardır. Bu sürenın sonunda saksilardaki topraklarin Ustten $5 \mathrm{~cm}$ ' lik kısimlari alınarak $1 / 1$ oranında (ağırlık lağırlık) destile su ile karıștirışmiş ve bir gece oda sicaklığında bekletilmiştir. Daha sonra sıvı faz ayrilarak 3 kez filitre kağıdından sozalmostar. Elde edilen bu sazokler sterilizasyon amaci lle por cap! $0,45 \mu \mathrm{m}$ olan sartorius bakteri filtresinden Leitz filtrasyon hunisi kullanilarak vakum yardımi ile tekrar süzölmüştúr. Bu toprak ekstraktları $145 \mu$ / $1 \mathrm{ml}$ PDA oranında ortama karıștırıimıştır. Herbir patojenin 7 günluk saf kütürlerinden alınan $5 \mathrm{~mm}$ çapındaki diskler toprak ekstraktı PDA ortamları içeren $9 \mathrm{~cm}$ lik petrilerin ortalanna gelecek şekilde aşılanmışlardır. Petriler $23 \pm 1$ ${ }^{\circ} \mathrm{C}$ de karanlikta 1 hafta sare lle inkube edilmișlerdir. Inkubasyon säresinin sonunda petrilerde gelişen kolonilerin çapları farklı 2 yơnde olçalmoș ve kaydedilmiștir.

Denemeler 5 tekerrürlu olarak yourutolmuştor ve 2 kez tekrarlanmıștir. Sonucların varyans analizleri ve LSD testleri MSTAT istatistik programi kullanilarak yapilmiștir.

Bltki artıklarını Bipolaris sorokiniana, Fusarium culmorum, Fusarium graminearum'un enfeksiyon oranlarına etkilerinin belirienmesi: Calişmanin bu aşamasında Fusarium culmorum, Fo graminearum ve Bipolaris sorokiniana inokulumlarinin hazirlanmasi amaci ile misır unu - kum ortam) ( $45 \mathrm{~g} \mathrm{kum}+5 \mathrm{~g}$ misır unut 10 lla $15 \mathrm{ml}$ destile su) kullanilmiștır (Nene ve Haware 1980)

$50 \mathrm{~g}$ kum-misır unu ortamı $250 \mathrm{ml}$ ' lik erlenmayerlerde sterilize edildikten sonra her bir patojenin PDA ortaminda geliștirilen 7 günlak költorlerinin kenar kısımlarından alınanan $7 \mathrm{~mm}$ çapindaki misel diskleri ile inokule edilmişlerdir. Erlenmayerler $25 \pm 1^{\circ} \mathrm{C}^{\prime}$ sicaklık ve 12 saat aydinlik, 12 saat karanlık periyot içeren inkubasyon odasında 15 gún inkabe edilmişlerdir. Her aç etmen için hazırlanan $50 \mathrm{~g}$ lik inokulumiar $1.5 \mathrm{~kg}$ steril olmayan tarla toprağı içeren saksılara ayrı ayrı karıştırıımışlardır. Bu sekilde inokule edilen topraklara $\% 1$ oranında (ağirık/ağırlik) bitki artıklarından ilave edilmiştir: Kontrol sakstlart sadece patojenlerle inokule edilmiş ancak herhangi bir bitki artığı ile muamele edilmemiştir. Bu sakilde hazırlanan saksılar \%5 oraninda (ağırlık/ağırlık) destile su ile nemiendirilmiš vo palietilen órtaler jle kaplanarak oda sıcaklığinda 5 hafta sure ile muhafaza edilmiştir. Bu surenin sonunda her saksıya 10 adet Bezostaja-l buggday tohumu ekilmiștir. Saksılar 12 saat aydinlık periyot ve $25 \pm 1{ }^{\circ} \mathrm{C}^{\prime}$ sicaklık içeren Iklim odalarına yerleştirilmiş ve dúzenli olarak sulanmıştir. Bitkiler 1 aylık gelişme sürecinin sonunda kökleri ile beraber sokoulmús, musiuk suyu altinda yikandiktan sonra hastalık belirtileri incelenmiştir.

Enfeksiyon oran, enfekteli bitkilerin sayısı belirlenerek hesaplanmıştır. Herbir uygulama 5 tekerrürí olarak yourōtölmüş, deneme iki kez tekrarlanmiștir. Sonuçlain değerlendirilmesinde MSTAT istatistik programı kullanilarak LSD testleri yapilmıștır.

\section{Bulgular ve Tartıģma}

Bitki artıklarınin Bipolaris sorokiniana, Fusarium culmorum, Fusarlum graminearum'un kültür geliģimine etkileri: Nohut, mercimek, arpa ve yulaf artıkları içeren toprak ekstraktları 7 günluk inkubasyon sûresinin sonunda B.sorokiniana'nin miseliyal gelișimini onemli oranda geriletmiştir. Yedi bitki artığından hiç biri F.culmorum'un koloni gelișimini engelliyememiş hatta nohut, mercimek ve buğday artıkları içeren toprak ekstraktları bu fungusun misel gelișiminl önemli oranda teşvik etmiştir. $F$. graminearum' un misel gelişiminin ise nohut artığı içeren toprak ektrakti ile teşvik edilirken, diğer bitki artıkları içeren toprak ekstraktları ile önemil oranda geriletildiği belirlenmiștir (Çizelge 1). Yulaf, mercimek, arpa, fiğ ve kolza'nın $B$, sorokiniana ve $F$ graminearum ' un her ikisinin de misel gelișimlerine engelleyici etkilerinin olduğu bu çalışmada saptanmıștır.

Elde edilen bu sonuçlar Singh ve ark. (1989) ve Dolar ve Demirci (1996)' nin bulgularina paralellik gosstermeistedir. Bu araştırıcılar mercimek, yulat, arpa, kolza ve fiğ artıklarının Fusarium oxysporum f.sp. cicent, $F$. solani, $F$. equiseti, $F$. moniliforme, Ascochyta rabiei ve Rhizoctonia solani' ye karşı etkili olduğunu, ayrica mercimek ve yulaf artiklarinin Rhizoctonia balaticola gelişimini engellediğini bildirmişlerdit. Bu sonuplar bitki artuklarinin toprakta dekompoze olması sırasında bazı kimyasal maddelerin oluștuğunu ve bunlarin Bipolaris sorokiniana, Fusarium culmorum ve $F$ graminearum' un gelişimini etkiledlğIni duşândormektedir.

Bitki artıklanın Bipolaris sorokiniana, Fusarium culmorum, Fusarium graminearum'un enfeksiyon oranlarına etkileri: Denemede kullanilan 7 bitki artığının tamami Fusarium culmorum, F. graminearum ve Bipolaris sorokiniana nın buğday bitkilerinde neden olduğu kbk enfeksiyon oranını onemli derecede azaitmıștır (Çizelge 2). B. sorokiniana ile enfekteli bitki sayısını mercimek artiklari llave edilen topraklarda $\% 60.46$ oraninda azaltilmıștir. Bunu sirasıyla, \% 60.29 luk bir azalmayıa nohut, \%58.82 lik azalmayla kolza ve \%49.67 lik azalma oranıyla da yulaf takip etmektedir. 
DEMIRCl, F. ve F. S. DOLAR, "Bitki artıklarının buğdayda'Bipolaris sorokiniana, Fusarium culmorum ve Fusarium graminearum'un neden olduğu kök çüräkügüne etkileri"

Çizelge 1. Farkli bitki artıkları içeren toprak ekstraktlarının Bipolanis sorokiniane', Fusarium culmorum ve F. graminearum'un misel gelişimine etkileri

\begin{tabular}{|l|c|c|c|}
\hline \multicolumn{1}{|c|}{ Bitki artiklart } & \multicolumn{3}{c|}{ Kontrole orania \% engelleme $(-$ ) veya \% teșvik $(+)$ değerleri } \\
\cline { 2 - 4 } & B. sorokiniana & F culmorum & F.graminearum \\
\hline Nohut & $-19.43(2.86)^{2}$ & $+7.01(9.00)$ & $+19.00(7.20)$ \\
Mercimek & $-22.25(2.76)$ & $+7.01(9.00)$ & $-24.79(4.55)$ \\
Buğday & $+3.66(3.68)$ & $+6.18(8.93)$ & $-21.15(4.77)$ \\
Arpa & $-17.46(2.93)$ & $+2.02(8.58)$ & $-21.32(4.76)$ \\
Kolza & $-3.94(3.41)$ & $+1.78(8.56)$ & $-14.87(5.15)$ \\
Fiğ & $-9.29(3.22)$ & $-0.95(8.33)$ & $-11.07(5.38)$ \\
Yulaf & $-22.53(2.75)$ & $-1.30(8.30)$ & $-15.37(5.12)$ \\
\hline Kontrol & $0.00(3.55)$ & $0.00(8.41)$ & $0.00(6.05)$ \\
\hline LSD(p=0.05) & 0.148 & 0.363 & 0.375 \\
\hline
\end{tabular}

arantez içindeki değerler koloni çaplari ortalamasıdir (mm)

Çizelge 2. Toprağa ilave edilen bitki artıkiarının sera koşullarında buğdayda Bipolarís sorokiniana, Fusarium culmorum ve F. graminearum 'un enfeksiyon oranı lzerine etkileri

\begin{tabular}{|l|l|l|l|}
\hline \multirow{2}{*}{ Birki artiklan } & \multicolumn{3}{|c|}{ Kontrole oranla enfeksiyon oranlarındaki \% engelleme $(-)$ değerieri } \\
\cline { 2 - 4 } & \multicolumn{1}{|c|}{ B. sorokiniana } & F. culmorum & \multicolumn{1}{c|}{ F. graminearum } \\
\hline Nohut & $-60.29(32.14)^{b}$ & $-47.99(32.00)$ & $-24.44(44.44)$ \\
\hline Mercimek & $-60.46(32.00)$ & $-59.36(25.00)$ & $-30.73(40.74)$ \\
\hline Bugday & $-35.57(52.15)$ & $-67.49(20.00)$ & $-8.92(53.57)$ \\
\hline Arpa & $-42.98(46.15)$ & $-41.49(36.00)$ & $-64.58(20.83)$ \\
\hline Kolza & $-58.82(33.33)$ & $-71.73(17.39)$ & $-41.15(34.61)$ \\
\hline Fiğ & $-21.98(63.15)$ & $-45.83(33.33)$ & $-43.33(33.33)$ \\
\hline Yulaf & $-49.67(40.74)$ & $-71.98(17.24)$ & $-49.64(29.62)$ \\
\hline Kontrol & $0.00(80.95)$ & $0.00(61.53)$ & $0.00(58.82)$ \\
\hline LSD (p=0.05) & 1.323 & 1.523 & 1.327 \\
\hline
\end{tabular}

- Hesaplama 100 bitki Czerinden yapilmıştır

Parantez içindeki değerler ortalama enfeksiyon oranidır (\%)

F.culmorum' da ise enfeksiyon oranı yulaf artıkları tarafindan kontrole oranla \%71.98, kolza artıkları ile $\% 71.73$ ve buğday artıklarıyla da $\% 67.49$ oranında azaltıimıştır.

F. graminearum'a karșı en etkili sonuç arpa artıkıarı içeren toprakta bulunmuştur. Bunu \%49.64 oranındaki azalmayla yulaf takip etmiştir. Çizelge 2'de görülebileceği gibi yulaf, arpa ve kolza artıkları her üc patojenin de neden olduğu buğday kök enfeksiyonlarını istatistiksel olarak önemli oranda azaltmıştır.

Vuratulen laboratuvar ve sera çalışmalarında elde edilen sonuçar $F$. culmorum haricinde birbirinl destekler niteliktedir. Laboratuvar denemelerinde bitki artıklarının F. culmorum' a herhangi bir engelleyicl etkisinin oimamasına karşın sera denemelerinde bu etmenin denemeye alınan tôm bitki artıklarınca istatistiksel olarak onemli oranda engellendiği belirlenmiştir. Synder ve ark. (1959) ile Davey ve Papavizas (1960) yaptıkları çalışmalarda arpa, buğday ve mısır artıkları ile ve soya fasúlyesi, mısır ve yulaf tanelerinın toprağa uygulanması ile fasalye kök çaraklağanan engellendiğini tespit etmişlerdir. Singh ve Nema (1987), yulaf ve buğday artıkları toprağa uygulandığında Rhizoctonia bataticola' nin topraktaki populasyonunun ve buna ilaveten nohutta oluşturduğu kok çaraklağo hastalık şiddetinin azaldığını bildirmișlerdir. Ramirez-Villapudua ve Munnecke (1988) ise, $F$. oxysporum f.sp. conglutinans'in topraktaki yoğunluğunun ve lahanalarda sarilık hastalığının şiddetinin, toprağa dokuz farklı lahanagil bitki artığının uygulanması ile azaltıldığını kaydetmişıerdir. Bitki artıklarının patojen enfeksiyonlarını engelleyici veya hastalık şiddetlerini azaltıcı etkileri bunların dekompoze oluşları sırasında açığa çıkan kimyasallarla direk olabileceği gibi topraktaki antagonistik organizmalar Uzerine olan olumlu etkileri ille indirekte olabilmektedir. Yoratalen bu çalışmada da ele alınan bitkisel artiklardan birçoğunun toprağa ilave edildiğinde denemede kullanilan buğday patojenlerinin neden olduğu enfeksiyon oraninı önemli ölçüde azalttığı görülmüş, ózellikle yulaf, arpa ve kolzanin diğerlerine kıyasla üç kök patojenine de daha etkili olduğu belirlenmiştir.

\section{Sonuç}

Bu çalışma sonucunda ôzellikle yulaf, arpa ve kolza artıklarınin Fusarium culmorum, F. graminearum ve Bipolaris sorokiniana' nın bugday bitkilerinde neden olduğu kök enfeksiyon oranını onemli derecede azaltığı tespit edilmiştir. Bu sebeple, bu patojenlerle mücadelede toprağa yulaf, arpa ve kolza artıklarının uygulanmasının başarilı sonuçlar vereceği kanısına varılmiştir. Yulaf, arpa ve kolzanın buğday ile munavebeye sokularak. hasat sonrası bitki artıklarının toprağa karıştırııması yolu ile bu buğday hastalıklarına karșı pratik ve çevre kirflitiğine yol açmayan bir múcadele olanağı elde edilebilir. 


\section{Teşekkür}

Denemede kullanilan Fusarium culmorum, $F$. graminearum ve Bipolaris sorokiniana izolatlarının temin edildiği Dr. Nihal Argun (Orman Bakanlığı. Orman Araştırma Enstitüsü, Ankara)'a teşekkür ederiz.

\section{Kaynaklar}

Anonim, 1998. 75. Yilında Sayılarla Türkiye Cumhuriyeti. Türkiye Cumhuriyeti Başbakanlık Devlet Istatistik Enstitüsù Matbaası, Ankara, $151 \mathrm{~s}$.

Davey, C. B. and G. C. Papavizas, 1960. Effect mature plant materials and nitrogen on Rhizoctonia solani in soil. Phytopathology, 50, 522-525

Dolar, F. S. and F. Demirci, 1996. Effect of crop residues on some of the chickpea pathogens. International Chickpea and Pigeonpea Newsletter, 3, 35-36

Gilpatrick, J. D. 1969. Effect of soil amendments upon inoculum survival and function in Phytophthora root rot of avacado. Phytopathology, 59, 979-985

Huber, D. M. and R. D. Watson, 1970. Effect of organic amendment on soil borne plant pathogens. Phytopathology, 60, 22-26

Huber, D. M. and G. R. Anderson, 1976. Effect of organic residues on snowmold of winter wheat. Phytopathology, 6,1028-1032.

Jarvis, W. R. and H. J. Thorpe, 1981. Control of fusarium foot and root rot of tomato by soil amendment with lettuce residues. Canadian Journal of Plant Pathology, 3, 159-162.

Linderman, R. G. 1989. Organic amendments and soil-borne diseases, Canadian Journal of Plant Pathology, 11,180-183

Mamluk, O. F., L. Çetin, H. J. Braun, N. Bulat, L. Bertschinger, K. M. Makhouk, A. F.Yıldırım, E. E. Saari, N. Zencirci, S. Albustan, S. Çalı, S. P. S. Benival and F, Düșünceli, 1997. Curent status of wheat and barley diseases in the Central Anatolian Planteau of Turkey. Phytopathologia Mediterranea, $36,167-181$.

Mauler-Machnık, A. and K. Zahn, 1994. Ear fusarioses in wheatnew finding on their epidemiology and control with Folicur (tebuconazole).Pflanzenschutz-Nachrichten Bayer, 47, 129155.

Nene, Y. L. and M. P. Haware, 1980. Screening chickpea for resistance to wilt. Plant Disease, 64, 379-380.
Ramirez-Villapudua, J and D. E. Munnecke, 1988. Effect of solar heating and soil amendments of cruciferous residues on Fusarium oxysporum f,sp. conglutinans and other organisms. Phytopathology, 7, 289-295.

Rush, C. M. and J. T. Mathieson, 1990. Effect of common root rot on winter wheat forage production. Plant Disease, 74, $982-$ 985.

Singh, D. and K. G. Nema, 1987. Effect of soil amendment on Rhizoctonia bataticola causing dry root rot of chickpea. International Chickpea Newsletter, 17, 23-25.

Singh, D., K. G. Nema and S. C. Vyas, 1989. Toxicity of some of the crop residues to soilborne pathogens of in vitro chickpeas. International Chickpea Newsletter, 21, 19-20.

Sun, S. and J. Huang, 1985. Formulated soil amendment fo controlling Fusarium wilt and other soilborne diseases. Plant Disease, 69, 917-920.

Synder, W. C., M. N. Schroth and T. Christon, 1959. Effect of plant residues on root rot bean. Phytopathology, 49, 755-756.

Weege, D., P. Poupard, U. Frei and V. Lind, 1991. Electrophoretic identification of pathogen-specific proteins of foot rot-inducing fungi of wheat. Journal of Plant Disease and Protection, 98, 112.

Wiese, M. V. 1987. Compendium of Wheat Diseases. 2nd edition, APS Pess. St. Paul, pp 124.

Williams-Woodward, J. L., F. L. Pfleger, V. A. Fritz and R. R. Allmaras, 1997. Green manures of oat, rape and sweet corn for reducing common root rot in pea (Pisum sativum) caused by Aphanomyces euteiches. Plant and Soil, 18,43-48.

Windels, C. E. and C. Holen, 1989. Association of Bipolaris sorokiniana, Fusarium graminearum group 2, and $F$. culmorum on spring wheat differing in severity of common root rot. Plant Disease, 73, 953-956.

lletişim adresi :

Fikret DEMIRCl

Ankara Óniv. Ziraat Fakültesi, Bitki Koruma Bölümü - Ankara

Tel : 0-312-3170550/1235

E.mail : fdemirci@agri.ankara.edu.tr 